\title{
Measurement of Ataxia and Related Neurological Signs in the Laboratory Rat
}

\author{
F. B. JOLICOEUR, D.B. RONDEAU, E. HAMEL, R.F. BUTTERWORTH AND A. BARBEAU
}

\begin{abstract}
SUMMARY: The purpose of the present study was to design a standard battery of tests capable of quantitatively characterizing ataxia and concomitant neurological signs in the rat. In addition to a systematic analysis of the walking gait of animals, tests for activity. catalepsy, rigidity, and various reflexive responses were included in the battery. The standardization and validation of the test system w'as performed $b y$ determining and comparing profiles of neurobehavioral effects produced by 3-acetyl pyridine, acrylamide, pyrithiamine, and thiamine deficiency, four experimental treatments reported to induce ataxia in animals. Results indicate that profiles of neurobehavioral disturbances accompanying ataxia in animals varied distinctively' w'ith each experimental treatment.
\end{abstract}

RÉSUMÉ: L'objectif de cette étude était de valider une batterie de tests conçue pour évaluer quantitavement chez le rat l'ataxie et les divers symptômes neurologiques l'accompagnant. En plus d'une analy'se détaillée de la démarche spontanée de l'animal, cette batterie comportait l'examen de certains réflexes ainsi que des tests mesurant l'activité motrice, la catalepsie et la rigidité musculaire. Les profiles neurocomportementaux produits par quatre modèles expérimentaux de l'ataxie, soit, l'administration de 3-acetyl pyridine, d'acrylamide, de pyrithiamine et la déficience en thiamine, furent comparés afin de déterminer la validité de l'ensemble de ces mesures. Les résultats indiquent des différences marquées entre les profiles et démontrent l'utilité de celte batterie de tests comme instrument descriminatif dans l'analyse expérimentale des syndromes ataxiques chez l'animal.

From The Clinical Research Institute of Montreal.

Reprint requests for the complete supplement on Friedreich's Ataxia (Phase Two, Part Two) to:

Dr. André Barbeau, Clinical Research Institute of Montreal, 110 Pine Avenue West, Montreal, Quebec, Canada, H2W IR7.

\section{INTRODUCTION}

Standard methods and procedures for detecting and measuring ataxia in experimental animals are generally lacking. Usually, reports of ataxic symptoms in animals are based on visual observations and are qualitative descriptions of these symptoms. Furthermore, examination of possible concomitant neurological signs in ataxic animals is rarely performed. There is a need for more systematic and quantitative methods for the detection and assessment of ataxia in laboratory animals. Such methods would provide research tools for investigating the differential neurobehavioral symptomatology and potential therapeutic manipulations of various models of ataxia in animals.

The purpose of the present study was to devise a standard battery of tests capable of quantitatively characterizing various signs of ataxia in the laboratory rat. The selection of the various tests was based on their proven ability to measure neurobehavioral changes induced by drugs or other experimental manipulations in animals.

The standardization and validation of the test battery was performed by determining and comparing profiles of neurobehavioral effects produced by four experimental treatments reported to produce ataxia in animals. The following animal models of ataxia were selected:

\section{3-Acetyl Pyridine}

A single injection of 3-acetyl pyridine in rats $(75 \mathrm{mg} / \mathrm{kg})$ produces within 24 hours signs of cerebellar ataxia and damage to the medulla oblongata and climbing fibers of the cerebellum (Desclin, 1974). Micro- scopic examination of the CNS reveals lesions as early as 7 hours after injection (Desclin and Escubi, 1974). The ataxia resembles, both histologically and biochemically, the olivocerebellar at rophy originally described by Holmes (1907). Recent studies have demonstrated that the lesions are associated with changes in the levels of certain amino acids in specific regions of the CNS (Butterworth et al., 1978).

\section{Acrylamide}

Chronic administration of acrylamide in doses of $10-50 \mathrm{mg} / \mathrm{kg}$ in animals results in peripheral neuropathy characterized by proprioception impairments, hindlimb paralysis, and progressive ataxia (Hamblin, 1956; Kuperman, 1957). Histopathological examination reveals distal axonal degeneration of peripheral motor and sensory nerve cells (Spencer and Schaumberg, 1974). The neuropathy is first seen with a cumulative dose of 400 $\mathrm{mg} / \mathrm{kg}$ and is most prominent with a cumulative dose of $500 \mathrm{mg} / \mathrm{kg}$ (Gipon et al. 1977).

\section{Thiamine Deficiency}

Chronic deficiency of vitamin $B_{1}$ results in pervasive metabolic and biochemical alterations in the nervous system. Thiamine deficiency ind uces a peripheral neuropathy of the "dying back" type that involves both sensory and motor nerve fibers (Schoental and Cavanagh, 1977). When rats are chronically fed a thiamine-free diet, a variety of disturbances such as anorexia, piloerection, tremors, kypokinesia and ataxia develop at about 30-40 days from the start of the diet (Yoshimura et al., 1976; McCandless et al., 1968). 


\section{Pyrithiamine}

Chronic administration of pyrithiamine, an antimetabolite of thiamine, results in central histopathological changes mostly localized in the pons and medulla oblongata (Yoshimura et al., 1976). Pyrithiamine also causes axonal degeneration of peripheral nerves (Yoshimura et al. 1976). Ataxic symptoms have been observed in animals injected daily for 18 days with , $0.5 \mathrm{mg} / \mathrm{kg}$ pyrithiamine (Gubler et al., 1974).

\section{METHODS}

\section{Animals}

Fifty four male Sprague Dawley rats, $275-350 \mathrm{~g}$ in weight, were used. They were divided into nine groups of six animals each. Food, which consisted of standard Purina Rat Chow, and water were available ad lib except when specified in the procedure.

\section{Procedure}

For 3-acetyl pyridine, two groups of animals were used. One group received an acute intraperitoneal injection of 75 $\mathrm{mg} / \mathrm{kg} 3$-acetyl pyridine dissolved in physiological saline. Volumes injected were $1 \mathrm{ml} / \mathrm{kg}$. Animals in the control group were injected with an equal volume of saline. Animals were tested for ataxia and other neurological symptoms at $6,12,24,48$ and 72 hours following injection.

Two groups of animals were included in the acrylamide model. Animals in the experimental group received ten successive daily injections of $50 \mathrm{mg} / \mathrm{kg}$ acrylamide. Control animals were injected with saline. Acrylamide was dissolved in physiological saline and administered intraperitoneally in a volume of 1 $\mathrm{ml} / \mathrm{kg}$. Starting on the second day of acrylamide administration, tests were carried out 30 minutes following the daily injection procedures.

For thiamine deficiency, one group of rats was given a thiamine-free diet (ICN Life Sciences, Nutritional Biochemical) throughout the experiment. Since this regime results in hypophagia with ensuing body weight loss, animals in the control group received standard rat chow in daily rations equivalent to the amounts consumed by the thiamine deficient animals. Tests were performed on days $7,14,21,27,30$ and 33. Starting on day 35 , tests were carried out daily until day 44.

To study the effects of pyrithiamine, three groups of animals were given the thiamine free diet and assigned to one of the following experimental treatments as described by Gubler et al. (1974). Pyrithiamine treated rats were administered $100 \mu \mathrm{g} / \mathrm{kg}$ of thiamine. These treatments were given daily for 18 consecutive days. All substances were dissolved in saline and administered subcutaneously in volumes of $2 \mathrm{ml} / \mathrm{kg}$. Animals were tested for neurological symptoms daily throughout the experiment.

\section{Neurobehavioral tests}

The neurobehavioral effects induced by the various treatments of this study were assessed by means of the following tests:

Locomotor activity: Spontaneous locomotor activity was measured for two minutes by means of a photocell activity apparatus (Lehigh Valley Electronics).

Catalepsy: Intensity of catalepsy was determined by a modification of the bar test described by Simon et al. (1969). An animal's front paws were placed on a horizontal wooden bar ( $1 \mathrm{~cm}$ in width) suspended $10 \mathrm{~cm}$ above the table. Time spent in that position, up to a maximum of 60 seconds, was recorded.

Rigidity: A rat was suspended by its front paws grasping a metal rod $(0.5 \mathrm{~cm}$ diameter $)$ which was held by the experimenter about $50 \mathrm{~cm}$ above the table. The time the animal remained on the bar (maximum $60 \mathrm{sec}$ ) was recorded. A prolonged grasping response has been correlated with direct measures of muscle rigidity (Steg, 1964).

Landing foot spread: After staining the hindpaws with ink, an animal was held horizontally $30 \mathrm{~cm}$ above a table covered with absorbent paper. The rat was dropped and the distance between the marks of each hindlimb was recorded. This procedure has proved to be useful in detecting peripheral neuropathy in rats (Lee and Peters, 1976).

Gait analysis: After staining the hindfeet with ink, an animal was walked through an enclosed $90 \mathrm{~cm}$ long corridor with a paper covered floor. When two consecutive strides were obtained, the stride width, length and angle between consecutive steps on contralateral sides were calculated. An illustration of this measuring procedure is presented in Figure 1.

Righting reflex: The animal was held by the tail and backflipped so that it somersaulted 2 or 3 times into the

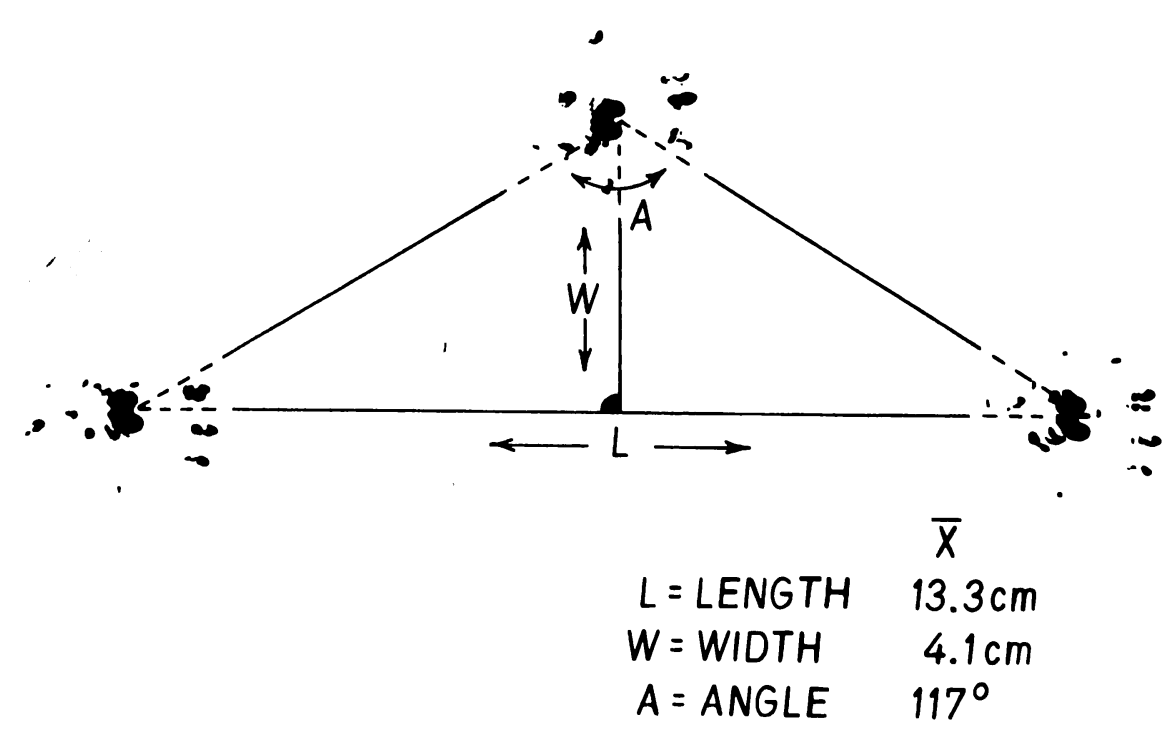

Figure I - Measurement of length (L), width (W) and angle (A) of steps in the analysis of rat's walking gait. A triangle is formed by drawing lines between steps. Mean values were obtained in six naive a nimals. 
air. The presence of normal (landing squarely on all four paws) or of abnormal righting response was recorded (Irwin, 1968).

Corneal reflex: The animal's cornea was touched lightly with the blunt end of a pencil and the presence of a normal eye blink was recorded (Irwin 1968).

Traction: An animal was held by the tail and pulled slowly on a table over a distance of about $60 \mathrm{~cm}$. A normal animal extends is limbs so that the underside of the body is not in contact with the table during the pull.

Forelimb extension: The rat was held by the tail at about $60 \mathrm{~cm}$ over a table top and lowered briskly towards the table. The presence or absence of a normal forward extension of the forelimbs during descent was recorded.

Hindlimb extension: An animal, placed on a table, was lifted by the tail so that the hind quarters were suspended at about $15 \mathrm{~cm}$ over the surface, with the forelimbs still resting on the table. The presence or absence of a normal extension of the hindlimbs was noted.

Hindlimb position: Animals were vertically suspended under the forelimbs. Postural abnormalities under this condition consist of foot dropping, crossed legs and curled toes (Snyder and Braun, 1977). The presence of any of these signs and of other abnormalities was recorded.

Weight shift: Rats were placed on a wire mesh cylinder. The cylinder was turned in one direction and the presence of a normal opposite weight shift was noted. This procedure was repeated by tilting the cylinder in the other direction.

Tail pinch: Pressure was applied to an animal's tail by means of a pencil. A normal response was recorded if the animal vocalized, jumped, or struggled.

\section{RESULTS}

On each model, data obtained on activity, catalepsy, rigidity, foot landing spread, and the three gait components were analysed by individual multifactorial ANOVA's for repeated measures (Winer, 1971). Factors included in each analysis were groups and test periods. When significant groups by test periods interactions were found, simple main effects analyses were carried out at each level of the test period factor to determine when groups differed significantly from each other. When appropriate, significant differences between individual groups were assessed by means of Dunnett and Tukey tests. Results obtained on the various reflex tests constituted nonparametric data and were analysed by means of Fisher Exact Probability tests (Siegel, 1956). For all statistical analyses, a difference between groups was considered significant if it had a probability of random occurrence of less than 5 percent.

\section{3-Acetyl Pyridine}

Results obtained at 6, 12, 24, 48 and 72 hours after 3-Acetyl Pyridine were included in the statistical analyses. It was found that 3-Acetyl Pyridine treated animals displayed significantly more catalepsy and muscle rigidity, and had larger landing foot spreads than control animals at each of the five test periods. The treated animals were also found to be significantly less active than controls 6 hours after the injection, but not at the other test periods. For the three components of gait analysis, no significant difference between the groups was found 6 hours after injection. However, starting at 12 hours and for the remainder of the post injection test periods, treated animals were consistently ataxic as revealed by significantly smaller angles and stride lengths as well as by larger widths between steps.

Analyses of the results obtained with the various reflex tests indicated the following significant effects: At 24, 48 and 72 hours, treated animals had lost the righting reflex and the ability to maintain a normal hunched posture during the traction test. Starting at 12 hours and enduring for the remainder of the experiment, treated animals displayed an abnormal hindlimb position characterized by the feet being retracted and held closely to the body. Finally a disturbance in the weight shift response of treated animals was found at the 72 hours post injection test period.

These results are summarized in Table 1 where significant group

TABLE 1

Occurrence of Neurological Symptoms in 3-Acetyl Pyridine (75 $\mathrm{mg} / \mathrm{kg})$ treated Rats

\begin{tabular}{|c|c|c|c|c|c|}
\hline & \multicolumn{5}{|c|}{ Hours } \\
\hline & 6 & 12 & 24 & 48 & 72 \\
\hline \multicolumn{6}{|l|}{ Gait Analysis } \\
\hline Length of steps & & $\bullet 1$ & $\bullet !$ & $\bullet !$ & $\bullet !$ \\
\hline Width of steps & & $\bullet \uparrow$ & $\bullet \uparrow$ & $\bullet \uparrow$ & $\bullet \uparrow$ \\
\hline Angle of steps & & $\bullet \downarrow$ & $\bullet !$ & $\bullet \downarrow$ & $\bullet !$ \\
\hline \multicolumn{6}{|l|}{ General Signs } \\
\hline Motor activity & $\bullet !$ & & & & \\
\hline Catalepsy & $\bullet$ & $\bullet$ & $\bullet$ & $\bullet$ & $\bullet$ \\
\hline Rigidity & $\bullet$ & $\bullet$ & $\bullet$ & $\bullet$ & $\bullet$ \\
\hline Landing foot spread & $\bullet \uparrow$ & $\bullet 1$ & $\bullet \uparrow$ & $\bullet \uparrow$ & $\bullet \uparrow$ \\
\hline \multicolumn{6}{|l|}{ Reflexes (Loss of ...) } \\
\hline Righting reflex & & & $\bullet$ & $\bullet$ & $\bullet$ \\
\hline Corneal reflex & & & & & \\
\hline Traction & & & $\bullet$ & $\bullet$ & $\bullet$ \\
\hline \multicolumn{6}{|l|}{ Forelimb extension } \\
\hline Hindlimb extension & NT & NT & NT & NT & NT \\
\hline Hindlimb position & & $\bullet$ & $\bullet$ & $\bullet$ & $\bullet$ \\
\hline Weight shift & & & & & $\bullet$ \\
\hline Tail pinch & & & & & \\
\hline
\end{tabular}

Full circle indicates significant difference from control group $(\mathrm{p}<0.05)$ Arrows indicate direction of change NT $=$ Not tested 
differences are presented for each test period.

\section{Acrylamide}

Data obtained in each of the nine daily test periods were included in the statistical analyses. In comparison to controls, acrylamide treated animals manifested significantly higher scores of catalepsy in all nine test periods. They also displayed significantly larger landing foot spreads than control animals in the fourth, sixth, seventh, eighth, and ninth test period. Significant gait disturbances in acrylamide treated animals were found on all test periods including the first test period following acrylamide administration. The ataxia was characterized by significantly smaller stride angle and length and by larger widths between steps. The activity and rigidity scores of acrylamide treated animals did not differ significantly from those of control animals.

Results on the various reflex tests revealed that, in acrylamide treated animals, the righting reflex was absent in the eighth and ninth test period and that the hindlimb extension response was impaired in the ninth test period. An abnormality in hindlimb position manifested by foot dropping and an inability to maintain a hunched position during the traction test were also found on the last test period. All other reflexes were unaffected by acrylamide.

These results are presented in Table 2 where significant group differences are given for each test period.

\section{Thiamine Deficiency}

The results were analysed in two parts. First, a statistical analysis was performed on the data obtained on days $7,14,21,27$, and 33 of the experiment. This analysis indicated that only transient and sporadic effects were produced during this initial phase of thiamine deficiency. On day 21 , thiamine deficient animals displayed significantly less locomotor activity than pair fed controls. A significant decrease in locomotion was also found on day 33 but not on day 27 . The gait angles and widths of deficient animals were respectively decreased and increased on day 27 while length of stride was unchanged. On day 33 stride length was significantly decreased in thiamine deficient rats but the other two gait parameters remained unaffected.

The second part of the analysis dealt with the final phase of the experiment, i.e. days 35 to 44 . During that phase, all thiamine deficient animals lost the righting reflex, displayed impaired weight shift responses, and eventually died. These effects were not seen in pair fed controls. The time of occurrence of the neurological symptoms and of death in the thiamine deficient group varied from animal to animal. Because of this, and in order to uniformly compare groups, the results obtained on days when individual thiamine deficient animals lost their righting reflex, were retained for analysis. Results collected in yoked pair fed controls on these days were also included in the analysis. No significant group differences were found for activity, catalepsy, rigidity, and landing foot spread. Also, aside from the righting reflex and weight shift response, no other reflexes were affected in thiamine deficient animals. Finally, gait analysis revealed that in thiamine deficient rats the angle and length of strides were significantly smaller than those of pair fed controls.

These results are summarized in Table 3 where all significant group differences are presented for each test period.

\section{Pyrithiamine}

Data obtained on days $1,3,6,9,12$, 15,16 , and 17 of pyrithiamine administration were included in the statistical analysis. No significant group differences were detected for activity and rigidity. The landing foot spread of pyrithiamine treated rats was significantly larger than thiamine deficient animals throughout the experiment, but did not differ significantly from controls. For catalepsy, the scores of pyrithiamine animals were significantly higher than controls on day 9. The catalepsy endured until the end of the experiment except for day 16 where differences between the two groups failed to reach statistical significance. Pyrithiamine had a minimal effect on the gait of treated animals. The width of steps in pyrithiamine treated animals was significantly larger than

TABLE 2

Occurrence of Neurological Simptoms in Acrylamide $(50 \mathrm{mg} / \mathrm{kg})$ treated Rats

\begin{tabular}{|c|c|c|c|c|c|c|c|c|c|}
\hline & \multicolumn{8}{|c|}{ Days } & \multirow[b]{2}{*}{9} \\
\hline & 1 & 2 & 3 & 4 & 5 & 6 & 7 & 8 & \\
\hline \multicolumn{10}{|l|}{ Gait Analysis } \\
\hline Length of steps & $\bullet !$ & $\bullet !$ & $\bullet !$ & $\bullet \downarrow$ & $\bullet !$ & $\bullet !$ & $\bullet \downarrow$ & $\bullet !$ & $\bullet 1$ \\
\hline Width of steps & $\bullet 1$ & $\bullet 1$ & $\bullet 1$ & $\bullet$ & $\bullet \uparrow$ & $\bullet$ & $\bullet$ & $\bullet i$ & $\bullet i$ \\
\hline Angle of steps & $\bullet !$ & $\bullet !$ & $\bullet !$ & $\bullet 1$ & $\bullet !$ & $\bullet !$ & $\bullet$ & $\bullet !$ & $\bullet !$ \\
\hline \multicolumn{10}{|l|}{ General Signs } \\
\hline Motor activity & & & & & & & & & \\
\hline Catalepsy & $\bullet$ & $\bullet$ & $\bullet$ & $\bullet$ & $\bullet$ & $\bullet$ & $\bullet$ & $\bullet$ & $\bullet$ \\
\hline Rigidity & & & & & & & & & \\
\hline Landing foot spread & & & & $\bullet 1$ & & $\bullet 1$ & $\bullet 1$ & - 1 & $\bullet 1$ \\
\hline \multicolumn{10}{|l|}{ Reflexes (Loss of ....) } \\
\hline Righting reflex & & & & & & & & $\bullet$ & $\bullet$ \\
\hline \multicolumn{10}{|l|}{ Corneal reflex } \\
\hline \multicolumn{10}{|l|}{ Traction } \\
\hline \multicolumn{10}{|l|}{ Forelimb extension } \\
\hline \multicolumn{10}{|l|}{ Hindlimb extension } \\
\hline \multicolumn{10}{|l|}{ Hindlimb position } \\
\hline \multicolumn{10}{|l|}{ Weight shift } \\
\hline Tail pinch & & & & & & & & & \\
\hline
\end{tabular}

Full circle indicates significant difference from control group $(p<0.05)$

Arrows indicate direction of change 
controls and this difference did not occur before day 17 of pyrithiamine administration. Similarly, reflexes were not affected until day 17 when pyrithiamine animals lost their righting reflex and their ability to maintain a normal body posture during the traction test.

Following the seventeenth injection the toxic effects of pyrithiamine precipitated. By day 18 two animals had died and the remaining rats were completely debilitated. In addition to the abnormalities found on day 17 . these animals were incapable of sustaining locomotion, lost the forelimb extension reflex and could not emit a normal weight shift response.

These results are presented in Table 4 where significant differences between the pyrithiamine treated animals and controls are given for each test day.

An overall summary of the results obtained with all four models is presented in Table 5. Schematic representations of rats' walking
TABLE 4

Occurrence of Neurological Symptoms Pyrithiamine $(0.5 \mathrm{mg} / \mathrm{kg})$ treated Rats

\begin{tabular}{|c|c|c|c|c|c|c|c|c|c|}
\hline & \multicolumn{9}{|c|}{ Days } \\
\hline & 1 & 3 & 6 & 9 & 12 & 15 & 16 & 17 & 18 \\
\hline \multicolumn{10}{|l|}{ Gait Analysis } \\
\hline \multicolumn{10}{|l|}{ Length of steps } \\
\hline \multicolumn{10}{|l|}{ Width of steps } \\
\hline \multicolumn{10}{|l|}{ Angle of steps } \\
\hline \multirow{2}{*}{\multicolumn{10}{|c|}{$\begin{array}{l}\text { General Signs } \\
\text { Motor activity }\end{array}$}} \\
\hline & & & & & & & & & \\
\hline \multicolumn{10}{|l|}{ Catalepsy } \\
\hline \multicolumn{10}{|l|}{ Rigidity } \\
\hline \multicolumn{10}{|l|}{ Landing foot spread } \\
\hline \multicolumn{10}{|l|}{ Reflexes (Loss of ....) } \\
\hline Righting reflex & & & & & & & & $\bullet$ & $\bullet$ \\
\hline Corneal reflex & & & & & & & & & \\
\hline \multicolumn{9}{|l|}{ Traction } & $\bullet$ \\
\hline \multicolumn{10}{|l|}{ Forelimb extension } \\
\hline \multicolumn{10}{|l|}{ Hindlimb extension } \\
\hline \multicolumn{10}{|l|}{ Hindlimb position } \\
\hline \multicolumn{10}{|l|}{ Weight shift } \\
\hline Tail pinch & & & & & & & & & \\
\hline
\end{tabular}

Full circle indicates significant difference from control group $(p<0.05)$ Arrows indicate direction of change IT = Impossible to test
TABLE 3

Occurrence of Neurological Symptoms in Thiamine Deficient Rats

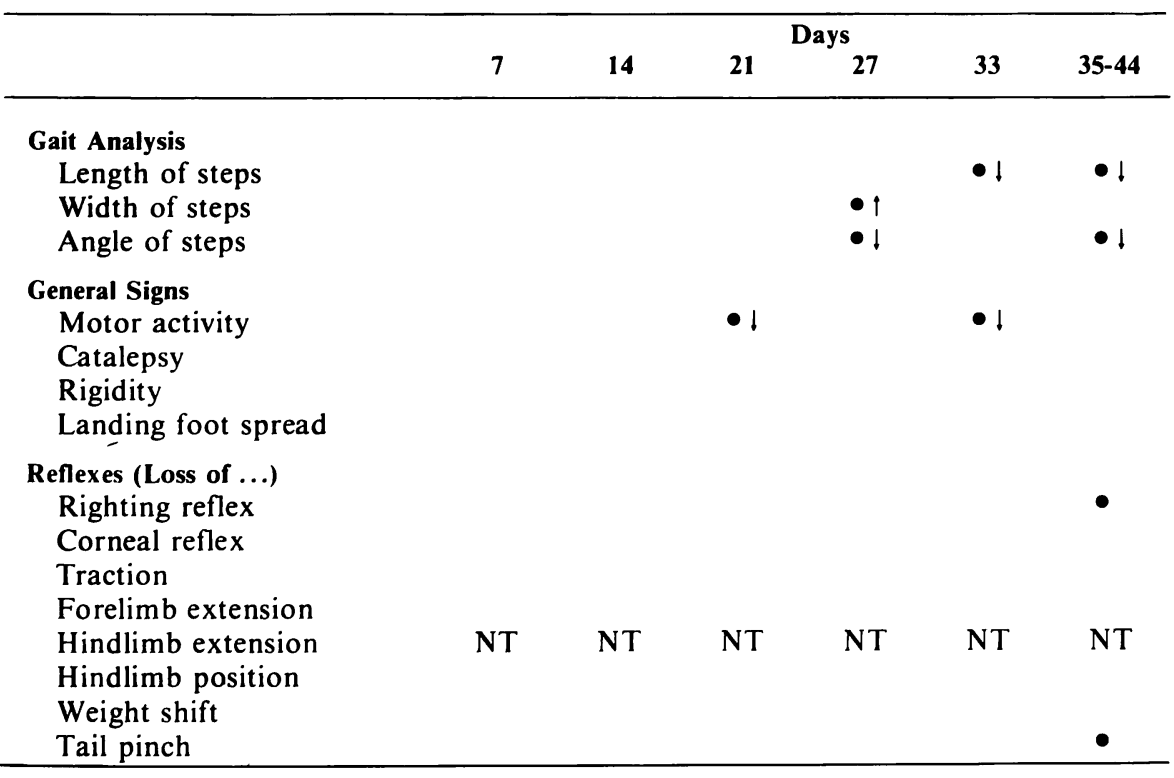

Full circle indicates significant difference from control group $(p<0.05)$

Arrows indicate direction of change

NT $=$ Not tested patterns obtained under the various treatments of this study are presented in Figure 2.

\section{DISCUSSION}

As expected, the four experimental treatments of this study induced ataxia as revealed by the gait analyses. However, the overall pattern of neurological signs accompanying the uncoordinated gait varied from treatment to treatment.

Of all treatments, 3-acetyl pyridine produced the most diversified effects (Table 5). This is not surprising in view of the known pervasive neurotoxic actions of this substance. A decrease in locomotor activity, an increase in landing foot spread, the presence of catalepsy as well as the appearance of distinctive muscle rigidity were found 6 hours after the administration of 3acetyl pyridine (Table 1). This latency in the effects closely parallels the known time course of neuropathological changes induced by this substance (Desclin and Escubi, 1974). 
TABLE 5

Summary. Table: Occurrence of Neurological Symptoms in all Treatments

\begin{tabular}{|c|c|c|c|c|}
\hline & \multicolumn{4}{|c|}{ Treatments } \\
\hline & $\begin{array}{l}\text { Thiamine } \\
\text { Deficient }\end{array}$ & Pyrithiamine & Acrylamide & $\begin{array}{l}\text { 3-Acetyl } \\
\text { Pyridine }\end{array}$ \\
\hline $\begin{array}{l}\text { Gait analysis } \\
\text { Length of steps } \\
\text { Width of steps } \\
\text { Angle of steps }\end{array}$ & $\begin{array}{ll}\bullet ! \\
\bullet \\
01\end{array}$ & $\bullet 1$ & $\begin{array}{ll}\bullet \\
\bullet \\
\bullet & 1\end{array}$ & $\begin{array}{ll}\bullet \\
\bullet \\
\bullet \\
\bullet !\end{array}$ \\
\hline $\begin{array}{l}\text { General Signs } \\
\text { Motor activity } \\
\text { Catalepsy } \\
\text { Rigidity } \\
\text { Landing foot spread }\end{array}$ & $\bullet !$ & $\bullet$ & $\begin{array}{l}\bullet \\
\bullet\end{array}$ & $\begin{array}{l}\bullet 1 \\
\bullet \\
\bullet \\
\bullet\end{array}$ \\
\hline $\begin{array}{l}\text { Reflexes (Loss of ...) } \\
\text { Righting reflex } \\
\text { Corneal reflex } \\
\text { Traction } \\
\text { Forelimb extension } \\
\text { Hindlimb extension } \\
\text { Hindlimb position } \\
\text { Weight shift } \\
\text { Tail pinch }\end{array}$ & NT & • & • & $\begin{array}{l}\bullet \\
\bullet \\
\text { NT } \\
\bullet \\
\bullet\end{array}$ \\
\hline
\end{tabular}

Full circle indicates significant difference from control group $(p<0.05)$

Arrows indicate direction of change

NT $=$ Not tested ataxic gait of acrylamide treated animals is not due to neuropathological changes but must be related to other unknown effects of acrylamide. The abnormalities observed in the righting, traction, and forelimb extension reflexes as well as in the hindlimb position may be more related to neuropathy since they did not occur until the eighth injection, which corresponds to a cumulative dose of $400 \mathrm{mg} / \mathrm{kg}$ of acrylamide. In the hindlimb position test, acrylamide treated animals displayed foot dropping, an effect not seen with the other treatments in this study. This unique symptom may explain the unusual gait of acrylamide treated animals in the final days of injection. As can be seen in Fig. 2, the pattern of gait of acrylamide treated animals is distinctively slanted to the right, suggesting that these animals had more difficulty in bringing back one hindlimb in completing a stride.

Contrary to expectations, thiamine deficiency and pyrithiamine did not
However, it is noteworthy that the first evidence of ataxia in this study was not found until the 12 hour test period following injection of 3-acetyl pyridine.

The effects of acrylamide were different in several aspects (Table 5). Ataxia and catalepsy were seen after the first injection of acrylamide while an increase in landing foot spread was not found until the fourth injection (Table 2). The induction of strong and persistent catalepsy by acrylamide was unexpected. This effect of acrylamide has not been reported and it indicates that this substance may have widespread pharmacological effects in the CNS, aside from its documented neuropathological actions in the periphery. The rapid onset of ataxia after a single injection of $50 \mathrm{mg} / \mathrm{kg}$ is surprising in view of the known dose related neuropathological effects of acrylamide. As mentioned earlier, evidence of peripheral neuropathy is first detected after cumulative doses of $400 \mathrm{mg} / \mathrm{kg}$ (Spencer and Schaumberg, 1974). This suggests that the early

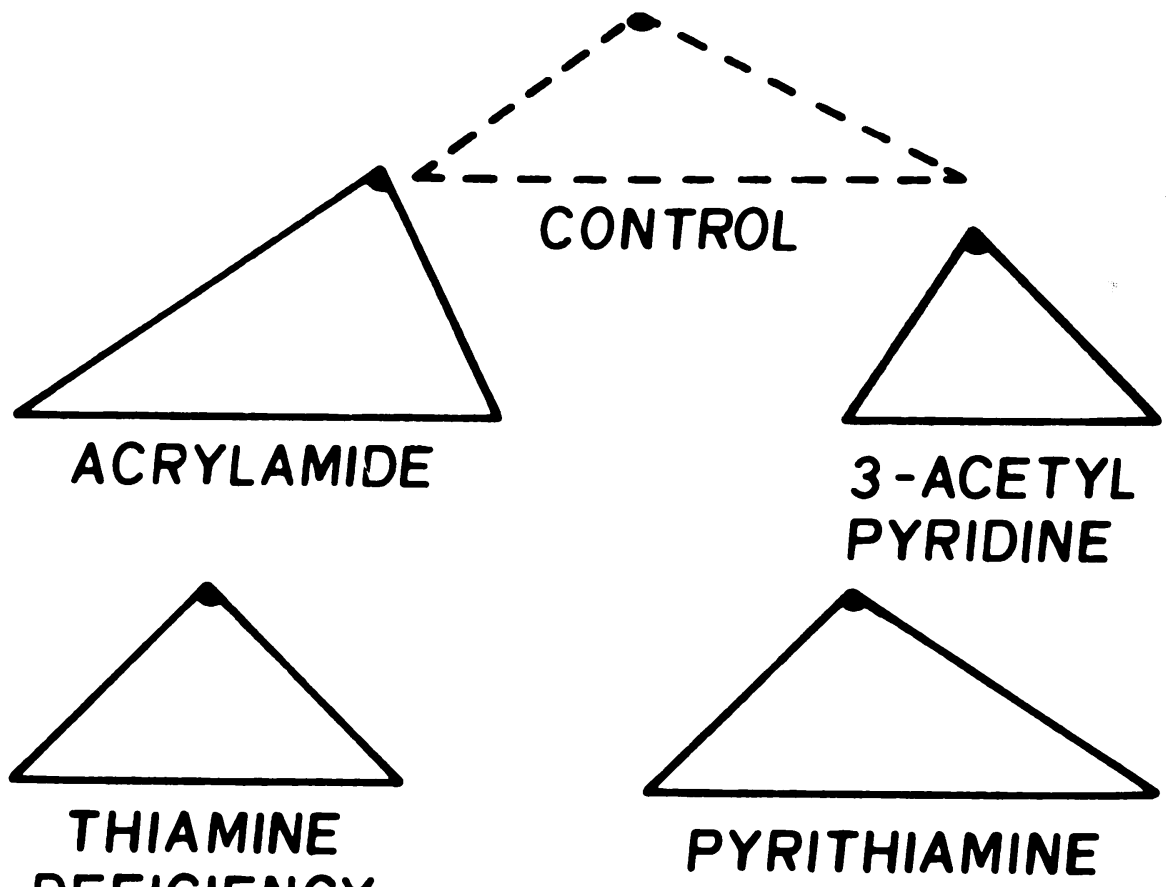

Figure 2-Schematic representations of gait of control and experimental animals in the four models of ataxia. Patterns were obtained in the final phases of each experimental treatment. 
yield similar neurobehavioral effects. Only the righting reflex and weight shift response were simiarly affected by both treatments. However, all three components of gait were disturbed in thiamine deficient animals while only the width of stride was altered in pyrithiamine treated animals. Thiamine deficiency, unlike pyrithiamine, decreased locomotor activity. Catalepsy as well as abnormal traction and forelimb extension reflexes were observed with pyrithiamine but not with thiamine deficiency. These striking discrepancies indicate that thiamine deficiency and administration of pyrithiamine, an antimetabolite of thiamine, affect the nervous system by distinct biochemical and/or neuropathological mechanisms.

Taken together, the results indicate that the battery of neurobehavioral tests used in this study constitutes a sensitive and reliable technique for detecting, quantifying, and differentiating various ataxic syndromes in experimental animals. The use of such a test system should prove to be valuable in future studies using animal models of ataxia.

\section{ACKNOWLEDGEMENTS}

The skillful technical assistance of Mr. F. Bélanger is gratefully acknowledged. We also want to express our appreciation to Miss Suzanne Gariepy for her valuable contribution in the preparation of the manuscript. F. B. Jolicoeur and D. B. Rondeau were supported by the Conseil de la Recherche en Santé du Québec and the Medical Research Council of Canada respectively.

\section{REFERENCES}

BUTTER WORTH, R. F., HAMEL, E. LANDREVILLE, F, and BARBEAU, A (1978). Cerebellar ataxia produced by 3 acetyl pyridine in rat. Can. J. Neurol. Sci. 5: 131-133.

DESCLIN, J. C. (1971). Histological evidence supporting the inferior olive as the major source of cerebellar climbing fibers. Brain Res. 77: 365-384.

DESCLIN, J.C. and ESCUBI, J.(1974). Effects of 3-acetyl pyridine on the central nervous system of the rat, as demonstrated by silver methods. Brain Res. 77: 341-364.

GIPON, L., SCHOTMAN, P., JENNEKINS, F. G. I. and GISPEN, W. H. (1977). Description of the acrylamide syndrome in rats. Neuropath. Appl. Neurobiol. 3: 115-123.

GUBLER, C. J., ADAMS, B. L., HAMMOND, B., YVAN, E. C., GUO, S. $M$. and BENNION, M. (1974). Effect of thiamine deprivation and thiamine antagonists on the level of gamma aminobutyric acid and on 2-oxogluterate metabolism in rat brain. J. Neurochem. 22: 831-836.

HAMBLIN, D. O. (1956). The toxicity of acrylamide. A preliminary report. S.E.D.E.S. Paris, 195-199.

HOLMES, G. (1907). A form of familial degeneration of cerebellum. Brain 30: 466-471.

IRWIN, S. (1968). Comprehensive observa- tional assessment. Psychopharmacologia 13: 222-257.

KUPERMAN, A. S. (1958). Effects of acrylamide on the central nervous system of the cat. J. Pharmacol. Exp. Ther. 123: 180-192.

LEE, C. C. and PETERS, P. J. (1976) Neurotoxicity and behavioral effects of thiamine in rats. Envir. Hlth. Persp., 17: 34-43.
McCANDLESS, D. S., SCHENKER, S. and COOK, M. (1968). Encephalopathy of thiamine deficiency. J. Clin. Invest. 47: 2268-2289.

SCHOENTAL, R. and CAVANAGH, J. B (1977). Mechanisms involved in the "Dying Back" process. Neuropath. Appl. Neurobiol. 3: $145-157$

SPIEGEL, S. (1956). Non parametric statistics for the behavioral sciences. New York: McGraw-Hill.

SIMON, P., LANGWINSKI, R, and BOISSIER, J. R. (1969). Comparaison de différents tests d'évaluation de la catalepsie chez le rat. Thérapie 24: 985-995.

SNYDER, D. R. and BRAUN, J. J. (1977). Dissociation between behavioral and physiological indices of organo-mercurial ingestion. Toxic. Appl. Pharmac. 41: 277-287.

SPENCER, P. S. and SCHAUMBERG, H. H. (1974). A review of acrylamide neurotoxicity Part II. Can. J. Neurol. Sci. I: 152-169.

STEG, G. (1964). Efferent muscle innervation and rigidity. Acta Physiol. Scand. 61, Suppl. $225,5-53$.

WINER, B. J. (1971). Statistical principles in experimental design. New York: McGrawHill.

YOSHIMURA, K., NISHIBE, Y., INOUE, Y. HIRONO, S., TOYOSHIMA, K. and MINESITA, T. (1976). Animal experiments on thiamine avitaminosis and cerebral function. J. Nutr. Sci. Vitaminol. 22: 429-437. 